\title{
ACESSIBILIDADE ESPACIAL EM AMBIENTES DE ENSINO BÁSICO: AS ESCOLAS MUNICIPAIS DE FORTALEZA
}

\author{
SANTIAGO, Zilsa Maria Pinto \\ Universidade Federal do Ceará, Doutora \\ e-mail: zilsa@arquitetura.ufc.br
}

\begin{abstract}
RESUMO
Trata de uma linha sucessiva de pesquisas e ações de extensão em três períodos de estudo, de 2003-2005; 2007-2008 e 2016, com o objetivo de avaliar as condições de acessibilidade espacial das escolas municipais de Fortaleza. De metodologias semelhantes, baseadas na Avaliação PósOcupação, restringindo-se a avaliação física por meio de vistoria in loco, com observação direta e registro fotográfico dos pontos positivos e negativos referentes às condições de acesso, circulação e uso dos ambientes e mobiliários da escola. O segundo apresenta algumas propostas de adequação das escolas. Os resultados mostram que não atingimos os objetivos da garantia de ir e vir das pessoas com deficiência no ambiente escolar, mas avanços estão sendo feitos no sentido de construir um ambiente mais inclusivo.
\end{abstract}

Palavras chave: acessibilidade espacial; arquitetura escolar; escola pública.

\begin{abstract}
It deals with a succession of surveys and extension actions in three study periods, from 2003-2005; 2007-2008 and 2016, in order to evaluate the spatial accessibility conditions of the municipal schools of Fortaleza. Similar methodologies, based on the Post-Occupancy Assessment, were restricted to physical evaluation by means of an on-site survey, with direct observation and photographic registration of the positive and negative points regarding the conditions of access, circulation and use of school environments and furniture. The second presents some proposals for the adequacy of schools. The results show that we have not achieved the goals of ensuring that people with disabilities come and go in the school environment, but progress is being made towards building a more inclusive environment.
\end{abstract}

Keywords: spatial accessibility; school architecture; public school.

\section{INTRODUÇÃO}

Falar de acessibilidade em escolas, nos remete às recomendações do MEC dos anos de 1970, onde encontramos o documento "Sugestões para Projetos de Escolas destinadas a Deficientes Físicos", CEBRACE/MEC (1977), tradução de documento do Ministério de Educação de Ontário, Canadá. Somente depois da Constituição Federal (1988), no entanto, a legislação sobre o assunto começa a se efetivar. Na Conferência Mundial de Educação Especial, realizada em junho de 1994, em Salamanca, foi reafirmado pelos governos e organizações internacionais participantes o compromisso da Educação para Todos, reconhecendo a necessidade e urgência de providenciar educação para as crianças, jovens e adultos com necessidades educacionais especiais dentro do sistema regular de ensino. A determinação da obrigatoriedade da inclusão do "portador de necessidades educacionais 


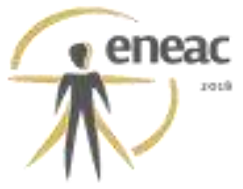

especiais" ${ }^{\prime 1}$ na rede regular de ensino, pela LDB Lei oํ 9.394/96 e a Lei № 10.098/2000, vieram reforçar a necessidade de uma estrutura física em espaços acessíveis a todos (SANTIAGO, 2005).

A partir dos estudos do Projeto Nordeste ${ }^{2}$ e em seguida do Fundescola ${ }^{3}$, o MEC divulgou, em 1998, padrões mínimos para escolas de ensino fundamental do Norte, Nordeste e Centro-Oeste ${ }^{4}$. Na verdade, os padrões lançados pelo MEC são diretrizes para que cada estado desenvolva o seu projeto-padrão.

Muitas outras Leis e Normas se sucederam, trazendo subsídios para melhor aparelhamento das escolas. O presente trabalho apresenta uma linha sucessiva de pesquisas e ações de extensão, priorizando três períodos de estudo, de 2003-2005; 2007-2008 e 2016, sobre as condições de acessibilidade espacial das escolas municipais de ensino fundamental em Fortaleza.

\section{ESCOLAS MUNICIPAIS DE ENSINO FUNDAMENTAL EM FORTALEZA CONSTRUÍDAS DE 1990 A 2003}

A pesquisa de mestrado da autora corresponde ao período de 2003 a 2005, quando investigou as condições de acessibilidade física das escolas municipais construídas entre 1990 a 2003 em Fortaleza. Justifica-se o recorte temporal para situar escolas construídas depois da elaboração da NBR 9050 em sua primeira versão de 1985, até o ano de inicio da pesquisa, 2003.

Constata-se que a acessibilidade nos edifícios escolares em Fortaleza vincula-se, inicialmente, às metas propostas pelo Plano Decenal da Educação (1993), tendo na Norma Técnica Brasileira (NBR 9050/94) diretamente e na legislação educacional (LDB Lei no 9.394/96), indiretamente, um reforço no sentido da inserção da acessibilidade nos projetos e adequações de escolas.

A rede municipal de ensino de Fortaleza contava em 2004, conforme site da Prefeitura, com 172 escolas patrimoniais de ensino fundamental, dentre elas, 62 construídas no período de 1990 a 2003, recorte temporal de interesse da pesquisa.

Para definir a distribuição das 62 escolas, verificou-se a localização de cada uma delas e a situação na Cidade em relação às Secretarias Executivas Regionais (SER), distribuindo-se da seguinte forma: 08 escolas na SER I; 02 escolas na SER II; 06 escolas na SER III; 07 na SER IV; 20 na SER V e 19 na SER VI. Em virtude da diversidade de tipologias das 62 escolas, foram identificadas e quantificadas. Isto foi feito através de consultas nos órgãos públicos municipais e de visitas in loco. Os grupos de tipologias foram identificados e

\footnotetext{
1 Termo utilizado no ambiente educacional se referindo aos alunos que necessitavam de algum atendimento especial, assim foram criadas Sala de Recursos Multifuncionais - SRMF, que são espaços físicos localizados nas escolas públicas onde se realiza o Atendimento Educacional Especializado - AEE. (SEESP/MEC, 2008).

${ }^{2}$ O Projeto de Educação Básica para o Nordeste (Projeto Nordeste) visava a superar os problemas, como baixos índices de aprendizagem, repetência e evasão escolar e implementar novos padrões de administração educacional.

${ }^{3}$ O Fundo de Fortalecimento da Escola (FUNDESCOLA) buscava, dentre outros objetivos, a criação de "Projetos Arquitetônicos Escolares Padronizados".

${ }^{4}$ Estes padrões também foram baseados em documento expedido pela FDE/SP - Fundação para Desenvolvimento de Educação do Estado de São Paulo. No Catálogo de Ambientes - Especificações da Edificação Escolar de Primeiro Grau - FDE/97 (6ª ed.), também já considera o banheiro especial para pessoas com deficiência nas especificações dos ambientes.
} 
quantificados, sendo calculada estatisticamente a quantidade amostral a ser visitada (Quadro 1).

\section{Quadro 1}

Quantidade, Tipologia das Escolas Municipais e quantidade amostral visitada

\begin{tabular}{|c|c|c|}
\hline Quant. & Tipologia & $\begin{array}{l}\text { Quantidade de } \\
\text { Escolas visitadas }\end{array}$ \\
\hline 34 & 1. Centros Municipais de Educaçăo e Saúde - CMES & 10 \\
\hline 10 & 2. Escolas do tipo: Modelo 12 Salas & 03 \\
\hline 06 & 3. Escolas Prè-moldadas & 02 \\
\hline 11 & 4. Projetos diferenciados & 04 \\
\hline 01 & 5. Escola Padrão-Ceará & 01 \\
\hline 62 & Total & 20 \\
\hline
\end{tabular}

Fonte: Santiago, 2005

Um dos mais negativos resultados encontrados foi o entorno da escola, calçadas com muitos desníveis, e inexistência de rebaixamento da calçada nas faixas de pedestre em frente à escola, como podemos ver nas Fotos 1, 2 e 3.

Foto 1: Entorno escola RMM desnível excessivo interrompendo a continuidade da circulação na calçada

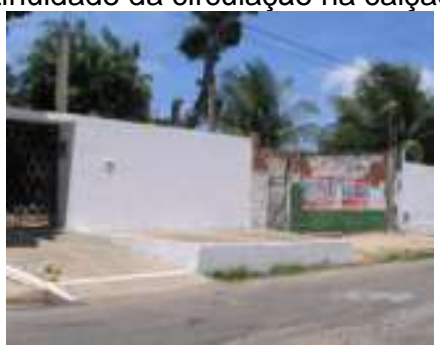

Fonte: Santiago, 2005
Foto 2: Entorno escola JSA desníveis consecutivos nas calçadas adjacentes à escola

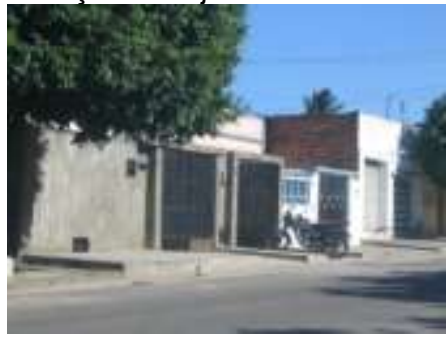

Fonte: Santiago, 2005
Foto 3: Escola RMM Faixa de pedestre sem rebaixamento de guia

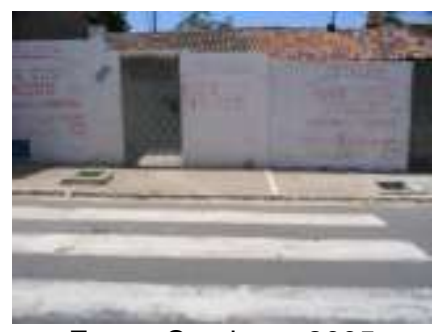

Fonte: Santiago, 2005

Com base na APO (Ornstein, 1992), para estudo das condições de acessibilidade das 20 escolas, foram avaliados os seguintes itens (com base na NBR 9050/1994), obtendo-se os resultados: 1. Calçada acessível no entorno da escola - 0\%; 2. Existência de faixa de pedestre - $25 \%$ possuem faixa de pedestre; 3 . Rebaixamento de guia - 30\%; 4 . Sinalização (SIA) - 0\% - Nenhuma escola apresentou; 5. Portão de entrada acessível - 90\%; 6. Hall da escola acessível - 80\%; 7. Circulação interna acessível - 70\%; 8. Acesso sala diretoria $100 \%$; 9. Acesso sala secretaria - $85 \%$; 10. Acesso sala professores - 100\%; 11. Acesso biblioteca - $10 \%$ não possuem biblioteca e $66,6 \%$ das existentes - acessíveis; 12 . Acesso sala de computação - $50 \%$ não possuem sala de computação e $80 \%$ das existentes acessíveis; 13. Acesso auditório - 95\% não possuem auditório e $100 \%$ da existente acessível; 14. Acesso pátio coberto - 90\%; 15. Acesso pátio aberto - $10 \%$ não possuem pátio aberto e $55.5 \%$ dos existentes acessíveis; 16 . Acesso algumas salas de aula no térreo - 100\%; 17. Acesso a todas salas de aula no térreo - 40\%; 18. Acesso sala de aula pavimento superior - 55\% não possuem pavimento superior e $22,2 \%$ dos existentes acessíveis; 19. Acesso refeitório - 30\% não possuem refeitório e 78,57\% dos existentes acessíveis; 20. Acesso mesa do refeitório - 30\% não possuem refeitório e $21,42 \%$ das existentes - acessíveis; 21. Alcance balcão atendimento secretaria - 20\%; 22. Alcance balcão atendimento cozinha/refeitório - 10\%; 23. Alcance telefone público - 0\%; 24 . Alcance bebedouro - 0\%; 25. Acesso quadra de esportes - 15\% não possuem quadra e 5,88\% das existentes - acessíveis; 26 . Acesso parque infantil - $80 \%$ não possuem parque infantil e $50 \%$ dos existentes - acessíveis; 27. Acesso banheiro - 30\%; 28 . Uso do lavatório - 40\% possibilidade de acesso; 29 . Uso do sanitário - 35\% possibilidade de acesso; 30 . Acesso estacionamento - $25 \%$ não possuem estacionamento e $60 \%$ dos existentes - acessíveis; 31 Piso alerta/tátil - 0\%; 32. Comunicação em Braille - 0\% (SANTIAGO, 2005). 


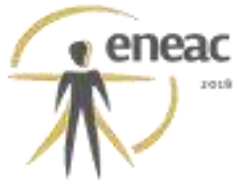

Ressalta-se que $80 \%$ das escolas não perfizeram $50 \%$ dos critérios de acessibilidade adotados, denotando que a acessibilidade é um problema de fato, existente nas escolas públicas municipais de Fortaleza, mesmo nas construídas entre 1990 e 2003.

\section{PERÍODO DE PESQUISA E AÇÕES DE EXTENSÃO - 2007- 2008}

No período de 2007 a 2008, em convênio com a Secretaria Municipal de Educação (SME), o grupo de estudo do Departamento de Arquitetura e Urbanismo/UFC realizou ações de extensão e pesquisa que culminaram em recomendações e projetos de adaptação de 39 escolas municipais patrimoniais. Uma delas, a escola modelo-padrão FUNDESCOLA, apresenta inadequações, por exemplo, o banheiro de funcionários, amplo, porém apresentava o sanitário no centro do banheiro, sem barras de apoio e sem espaço de aproximação lateral para o módulo de referência $0,80 \times 1,20 \mathrm{~m}$ (Foto 4). Para adequação, foi entregue à SME projeto de adaptação para reforma (Figura 1). Outro ponto a ressaltar é a posição das grelhas na direção da circulação e o espaçamento entre elas, maior que o recomendado pela Norma (Foto 5).

Foto 4: Escola Odilon Braveza

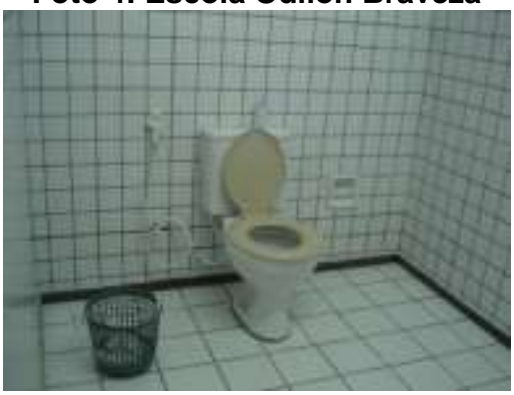

Fonte: Arquivo da Pesquisa/Extensão, 2007
Figura 1: WC adaptado

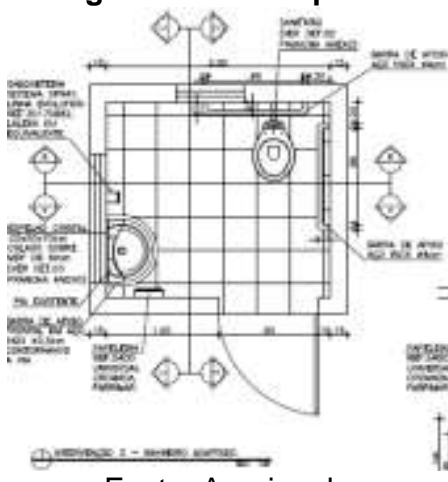

Fonte: Arquivo da

Pesquisa/Extensão, 2007

\section{FOTO 5: Escola Odilon Braveza}

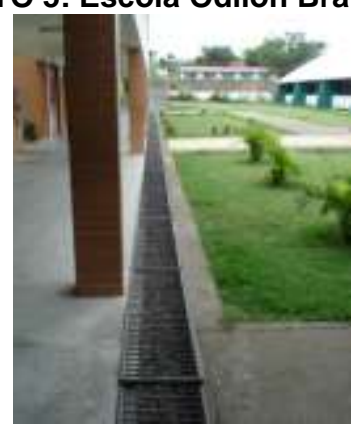

Fonte: Arquivo da Pesquisa/Extensão, 2007

O projeto original do modelo-padrão FUNDESCOLA continha plataforma elevatória e não rampa de acesso ao segundo pavimento. Com problema dos custos de manutenção, foi pensado pela SME, a inserção de uma rampa, substituindo a plataforma (Figura 2).

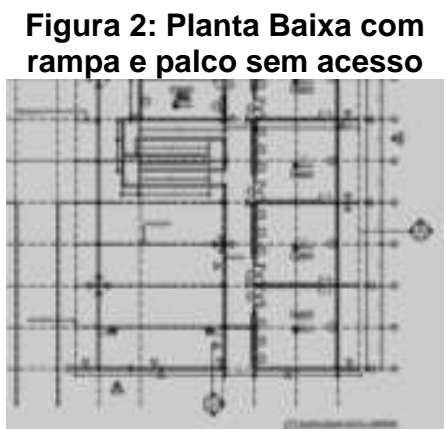

Fonte:FUNDESCOLA/SME/PMF, 2007
Figura 3: Planta Baixa com mudança de local da rampa e palco acessível

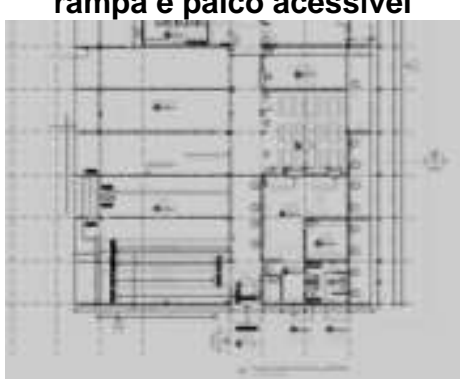

Fonte: SME/PMF, 2008

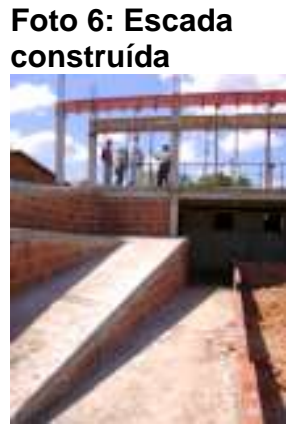

Fonte: Arquivo Pesquisa/ Extensão, 2008

Em visita à escola, dentre o diagnóstico e recomendações, verificamos a questão da rampa de acesso ao pavimento superior, quando foi sugerido, deslocar a rampa para a parte posterior do palco, sendo o primeiro trecho da rampa, o acesso ao palco. (Figuras 3). Esse período teve como impacto a mudança no projeto da rampa e do banheiro. 


\section{PERÍODO DE PESQUISA E AÇÕES DE EXTENSÃO - 2016}

Em 2016 foram estudadas sete escolas no Bairro Bom Jardim, Projeto de Extensão/UFC coordenado pela autora, em parceria com o Projeto Arvore(ser) da Faculdade de Direito/UFC, coordenado pela Professora Dr. ${ }^{\text {a }}$ Beatriz Xavier e com o Núcleo de Defesa da Educação - 16 ${ }^{\underline{a}}$ Promotoria de Justiça Cível do Ministério Público do Estado do Ceará (MPCE), sob a coordenação da Promotora Dr. ${ }^{\text {a }}$ Elizabeth Oliveira. Objetivo do projeto analisar situação de inclusão na sala de Atendimento Educacional Especializado (AEE) e as condições de acessibilidade espacial das escolas. De um modo geral o resultado foi bem negativo, assim, verificamos as potencialidades de adequação, sendo a Escola Santos Dumont, a de maior potencial de adequação.

\section{CONSIDERAÇÕES FINAIS}

Verificamos que em três períodos distintos encontramos espaços escolares com inconformidades de atendimento às questões de acessibilidade. Os trabalhos de pesquisa $e$ de extensão mostraram as inadequações das escolas municipais, o que se considera merecer por parte do setor público responsável pelos projetos, construções e reformas, maior atenção no quesito "acessibilidade" para pessoas com deficiência e mobilidade reduzida. Ressalta-se ainda que os três períodos analisados se constituem, de certa forma, uma linha crescente de ação, tendo no primeiro uma pesquisa empírica de situação; no segundo, além do diagnóstico, sugere-se alguma intervenção de projeto; e no terceiro, o conhecimento dos laudos por parte do Ministério Público terá um impacto diferenciado nas audiências junto à Secretaria Municipal de Educação. O que mostra a transversalidade das questões de acessibilidade espacial e sua importância como fator de inclusão.

\section{REFERÊNCIAS BIBLIOGRÁFICAS}

ASSOCIAÇÃO BRASILEIRA DE NORMAS TÉCNICAS. NBR 9050: Acessibilidade a edificações, mobiliário, espaços e equipamentos urbanos. Rio de Janeiro, 1994; 2014; 2015.

BRASIL. Decreto № 5.296, de 2 de dezembro de 2004, que regulamenta as Leis $n^{\circ}=\mathrm{s} 10.048$, de 8 de novembro de 2000, que dá prioridade de atendimento às pessoas que especifica, e 10.098, de 19 de dezembro de 2000, que estabelece normas gerais e critérios básicos para a promoção da acessibilidade das pessoas com deficiência ou com mobilidade reduzida, e dá outras providências.

Conferência Mundial de Educação Especial. Salamanca, 1994.

MEC. LDB Lei no 9.394, de 20 de dezembro de 1996. Estabelece as diretrizes e bases da educação nacional.

MEC. Plano Decenal de Educação para Todos. Brasília: MEC, 1993.

MEC. CEBRACE/MEC. Sugestões para Projetos de Escolas destinadas a Deficientes Físicos. tradução de documento do Ministério de Educação de Ontário, Canadá. Brasília: CEBRACE, 1977.

ORNSTEIN, Sheila; ROMÉRO, Marcelo. Avaliação Pós-Ocupação (APO) do ambiente construído. São Paulo: Studio Nobel; Editora da Universidade de São Paulo, 1992.

SANTIAGO, Z. M. P. Acessibilidade física no ambiente construído: o caso das escolas municipais de ensino fundamental de Fortaleza-CE (1990 - 2003). Dissertação de Mestrado. FAUUSP, São Paulo, 2005.

SANTIAGO, Z. M. P. Relatório Anual de Projeto de Extensão - Projeto Acessibilidade em Escolas de Ensino Fundamental e Médio das Redes Públicas Estadual e Municipal. Fortaleza: PREX, 2016.

https://acessoescola.wordpress.com/projetos-das-escolas/ Acesso em 10/02/2018.

www.fortaleza.ce.gov.br Acesso em 09/02/2004. 